\title{
SCALAR IMPLICATURES IN COMPLEX SENTENCES *
}

\begin{abstract}
This article develops a Gricean account for the computation of scalar implicatures in cases where one scalar term is in the scope of another. It shows that a cross-product of two quantitative scales yields the appropriate scale for many such cases. One exception is cases involving disjunction. For these, I propose an analysis that makes use of a novel, partially ordered quantitative scale for disjunction and capitalizes on the idea that implicatures may have different epistemic status.
\end{abstract}

\section{INTRODUCTION}

\subsection{A Starting Point: Gazdar's Account}

Building on ideas of Grice (1967) and Horn (1972), Gazdar (1979) develops a general account of scalar implicatures. This general picture has been widely accepted (see e.g., the textbooks by Levinson (1983, pp. 132136) and Gamut (1991, pp. 204-209)). To illustrate these ideas consider the examples in (1) and (2).

(1) Kai had peas or broccoli last night.

$\sim$ Kai didn't have peas and broccoli last night.

(2) Kai had some of the peas last night.

$\sim$ Kai didn't have all of the peas last night.

$\star$ The ideas in this paper developed out of my reactions to two separate presentations by Gennaro Chierchia and Bernhard Schwarz at Tübingen University in October 2000 and subsequent discussions with both of the authors. I am very grateful to both of them for their insights and their willingness to discuss these issues with me. Kai von Fintel also deserves special thanks for making it clearer to me what I was saying and how it relates to what other people have said. An earlier version of this paper was presented at the Workshop on Formal Pragmatics at the Zentrum für allgemeine Sprachwissenschaft in Berlin. I also thank Manfred Krifka, Laurence Horn, Irene Heim, Ede Zimmermann, Robert van Rooy, Winnie Lechner, Fritz Hamm, Kazuko Yatsushiro, Martin Hackl, Danny Fox, and Elena Guerzoni for useful comments along the way, and Katrin Petodnig and Oliver Bott for correcting several typos. Finally, I am grateful to the three anonymous reviewers and the editor, Laurence Horn, whose detailed comments helped me to improve thepaper substantially. All remaining errors are solely my own responsibility.

Linguistics and Philosophy 27: 367-391, 2004.

(C) 2004 Kluwer Academic Publishers. Printed in the Netherlands. 
In the following, I use the notation $\phi \leadsto \psi$ to indicate that $\psi$ is an implicature of $\phi$ in the way already employed in (1) and (2).

Grice (1967) uses one test for the presence of a scalar implicature: namely, that examples like (1) and (2) are infelicitous assertions unless the implicatures in (1) and (2) are satisfied. Horn (1972) points out a number of further tests for the presence of a scalar implicature. One of Horn's tests using what he calls suspender clauses is illustrated in (3). Horn (1972, p. 30 ) argues that continuations of a sentence $\phi$ with and possibly ... even $\psi$ are acceptable only if the negation of $\psi$ is a scalar implicature of $\phi$. The acceptability of (3) shows therefore that (1) indeed has the indicated "not-and"-implicature, which I'll call the exclusivity implicature.

(3) Kai had peas or broccoli, and possibly Kai even had peas and broccoli.

The exclusivity implicature of (2) is the most salient one of this example. One interesting feature of this scalar implicature is that it is independent of the discourse context in which (1) appears, ${ }^{1}$ while Hirschberg (1985) and Matsumoto (1995) show that in specific discourse contexts sometimes further scalar implicatures become available. ${ }^{2}$ In this paper, I'm concerned only with scalar implicatures that are independent of a specific context like the exclusivity implicature of disjunction. Logical words like or and some generally seem to give rise to such context-independent scalar implicatures.

Gazdar (1979, pp. 57-61) proposes a precise mechanism for the computation of scalar implicatures (similar descriptions have been given by Horn 1989, p. 214; Atlas and Levinson 1981, p. 33; Levinson 2000, p. 76). It relies on the notion of a quantitative scale that Horn (1972) introduced. Gazdar's mechanism applies only to sentences $\phi$ where an expression from a quantitative scale $\alpha$ appears not in the scope of any logical operator. I'll

1 Of course, example (1) has more implicatures that are independent of context. For example, Gazdar (1979) points out that disjunctions generally imply, that both disjuncts must be possible. For example (1), this amounts to the implicatures in (i).

(i) $\sim$ It's possible that Kai had peas last night.

$\sim$ It's possible that Kai had broccoli last night.

I discuss these particular implicatures in Section 3.2 where they become relevant.

2 One such context for (1) is the following: Kai's parents promise him rewards for certain things he does not like to do: for washing his hair he gets a small reward, for eating broccoli or peas he get a medium reward, and for cleaning up his room he gets a big reward. In this scenario, (1) uttered at bed-time by one of Kai's parents implicates that Kai did not clean up his room. 
write this as $\phi=f(\alpha)$. Gazdar's mechanism predicts an implicature for $\phi$ if $\alpha$ is not the maximal item on its quantitative scale $Q$. In this case, let $\alpha^{\prime}$ be the word that is following $\alpha$ on $Q$. The mechanism forms $\psi$ $=f\left(\alpha^{\prime}\right)$ by replacing $\alpha$ with $\alpha^{\prime}$ in $\phi$. Finally, the scalar implicatures of $\phi$ generated are all expressions $\mathrm{K} \neg \psi$ for any $\psi$ that can be derived in the way just described. $K$ here is an epistemic certainty operator (Hintikka 1962) expressing that the speaker is certain about the argument of K. Hence, the implicatures of $\phi$ can each be paraphrased as The speaker is certain that $\psi$ is false. $^{3}$

Consider the examples in (1) and (2) for an illustration. The quantitative scales required in the account of (1) and (2) are $\langle$ or, and $\rangle$ and $\langle$ some, all $\rangle$. In each of the examples (1) and (2), there is only one possible replacement to consider, so there is also only one scalar implicature predicted in each example. The implicature assigned to (1) is then $\mathrm{K} \neg$ Kai had peas and broccoli last night and the one assigned to (2) is $\mathrm{K} \neg$ Kai had all of the peas last night. This result corresponds to the intuitions about (1) and (2) noted above.

\subsection{Limitations of Gazdar's Account}

Gazdar's procedure is very limited since it only applies to cases that like (1) and (2) contain scalar terms not in the scope of a logical operator. This predicts that scalar terms in the scope of a logical operator should never trigger any implicatures. However, this prediction is incorrect as other people have noticed before me (Atlas and Levinson 1981; Hirschberg 1985; Horn 1989; Harnish 1976). The problems mostly discussed are scalar terms in the scope of negation: While Gazdar's mechanism predicts no implicatures in this case, examples like (4) clearly have an implicature that seems due to the use of the scalar item all.

(4) Kai didn't have all of the peas last night.

$\leadsto$ Kai had some of the peas last.

The generalization Atlas and Levinson (1981) and Horn (1989) suggest is that negation reverses scales.

Though the problem of negation is most often discussed, equally serious problems actually arise also in examples without negation and

\footnotetext{
${ }^{3}$ Gazdar (1979) distinguishes in his terminology between the potential implicatures of a sentence and its actual implicatures. The mechanism described here only yields potential implicatures. They become actual implicatures of a particular sentence only if they are not cancelled by one of Gazdar's implicature cancellation conventions. My use of terminology in the text therefore is sloppy, but I believe sufficiently clear for my purposes.
} 
downward entailing operators. In particular, there is a problem extending Gazdar's procedure to cases with disjunction and another operator in its scope. This problem in its full generality was brought to my attention by Chierchia (2002) and Schwarz (2000), who apparently discovered this problem independently. ${ }^{4}$ Consider example (5), which looks like an innocent combination of (1) and (2).

(5) Kai had the broccoli or some of the peas last night.

As we shall see, (5) is actually a serious challenge for the theory of implicatures. Consider first what Gazdar predicts: Since Gazdar's mechanism can only apply to occurrences of scalar terms not in the scope of any other logical operator, it only applies to or in (5). The occurrence of some in (5) is in the scope of or and therefore not in the domain of Gazdar's mechanism. Therefore, only one implicature is predicted for (5), namely the one given in (6).

(6) (5) $\leadsto$ Kai didn't have the broccoli and some of the peas last night.

While this implicature is intuitively correct, both (5) and (6) are true in a situation where Kai ate all of the peas and no broccoli last night, and therefore, (5) should be a felicitous utterance in such a situation. But this does not seem to be right. If you were to utter (5), while I knew for a fact that Kai had all the peas last night, I would think you are wrong. Hence, in such a scenario, I would use (7a) in my reply to you, rather than (7b).

(7)a. No, he had all of the peas last night.

b. \#Yes, he had all of the peas last night.

So, there seems to be at least one other implicature that is drawn from (5). For example, if (8) could be drawn as an implicature from (5) this would capture the intuition just observed.

(8) $\quad(5) \sim$ Kai did not have all of the peas last night.

But, how to arrive at something like (8)? This paper is an attempt to do just this.

\footnotetext{
4 A special case of this puzzle, namely the case of a disjunction in the scope of disjunction, seems to be aimed at by McCawley (1993, p. 324) in an exercise and is discussed by Simons (1998, pp. 88-96) (see Section 3.3).
} 


\subsection{Hirschberg's Extension}

Hirschberg (1985, pp. 720-74) makes to my knowledge the only general proposal to overcome the shortcoming of Gazdar's (1979) account just noted. She rightly points out that scalar expressions in the scope of logical functors in many cases yield scalar implicatures contrary to the predictions of Gazdar's account. Hirschberg therefore concludes that Gazdar's claim that all logical functors block scalar implicatures from scalar terms in their scope needs to be revised. She proposes that only negation blocks scalar implicatures, while scalar implicatures should be computed by Gazdar's mechanism in all other cases.

One of Hirschberg's examples corroborating her proposal is (9). Gazdar's account here incorrectly would not predict the indicated implicature, but Hirschberg's does.

(9) It's possible that Paul ate some of the eggs (Hirschberg 1985, (75a)).

$\sim$ It's not possible that Paul ate all of the eggs.

But Hirschberg's proposal has problems of its own: It still does not predict the implicature reversal under negation. Furthermore, it overgenerates in cases of a scalar term in the scope of disjunction. In fact, Hirschberg discusses one such case, namely (10); however, as I will argue, her discussion is flawed.

(10) Paul ate some of the eggs or Paul is a liar.

Gazdar's proposal, as discussed in the previous section, only predicts an exclusivity implicature for (10), which we saw to be insufficient. Hirschberg's proposal predicts an additional implicature that is generated by replacing some with all, which is the next higher item on its scale. The result is the putative implicature in (11) (cf. Hirschberg 1985, (75b)).

(11) It's not the case that Paul ate all of the eggs or is a liar.

But, (11) cannot be an implicature of (10). Importantly, Hirschberg's proposal predicts negation to take wide scope over the disjunction in (11). (To make (11) unambiguous, I dropped the subject in the second disjunct.) Therefore, (11) is equivalent to the easier to understand (12) by De Morgan's law.

(12) Paul didn't eat all of the eggs and Paul isn't a liar. 
The equivalence to (12) makes it clear that the implicature (11) Hirschberg predicts is too strong: (11) entails that Paul is not a liar, while actually the sentence (11) would be infelicitous if it was known that Paul is not a liar. ${ }^{5}$ Note that even if Hirschberg were to argue that the implicature (11) was cancelled by some further mechanism, her account would still be insufficient since it would then not generate more implicatures for (10) than Gazdar's proposal. But, the discussion of example (5) above has shown already examples of this type have at least one additional implicature, namely for (10) the one in (13).

(13) $\quad(10) \sim$ Paul didn't eat all of the eggs.

\subsection{Contributions of this Paper}

As the problems of Hirschberg's account show and as also Chierchia (2002) argues, it is not obvious how to extend something like Gazdar's procedure to cases where a scalar term appears in the scope of another logical operator. Therefore, Chierchia dismisses the entire picture of Grice (1967) and develops one of his own. ${ }^{6}$ My goal in this paper is to show that such a radical break is unwarranted: I will show that the disjunction problem can be solved within Grice's framework.

This paper makes two contributions that are of a more technical nature. On the one hand, I show that in general the implicatures of sentences containing more than one scalar expression are computed by forming something akin to the crossproduct of the two scales. On the other hand, I will argue that the scale of disjunction is not just 〈or, and〉, but rather is a set that is only partially ordered by entailment and contains the items "A or B", "A", "B", and "A and B". Furthermore, I provide some fairly direct empirical evidence for the claim of Soames (1982), Horn (1989) and others that implicatures are epistemically modalized.

\footnotetext{
5 Later in the thesis, Hirschberg (1985) actually modifies her account of scalar implicatures further. Namely, she adopts the proposal that scalar implicatures represent uncertain knowledge (see Section 3.2 for further discussion). As one reviewer pointed out to me, Hirschberg's account with that modification does not predict (11) as an implicature any more, though Hirschberg herself claims explicitly that (11) is an implicature of (10). Since Hirschberg does not discuss (11) in this part anymore, it is not clear what prediction she actually intends.

6 Because at the time of my writing Chierchia's paper is unpublished, I will not discuss his proposal fully or compare it with mine. In its present form, I believe Chierchia's proposal has some technical problems that no doubt will be resolved in the final version. In 4.1, I discuss the other evidence Chierchia claims to be problematic for the Gricean approach.
} 
I should mention that there is one important question that I have nothing to say about here: Namely, the question where quantitative scales come from. I shall here simply take quantitative scales for granted and use them to account for the implicatures of sentences. See Hirschberg (1985) and Matsumoto (1995) for some interesting suggestions relating to this question.

\section{Crossing Scales}

\subsection{A Small Improvement}

What implicatures are drawn from examples with a scalar term in the scope of a logical operator? One initial problem to overcome is to deal with scalar terms in the scope of negation. Consider example (14) from Gazdar (1979). ${ }^{7}$ Here, the simple-minded application of Gazdar's procedure would, by replacing some with all and negating the result (where then the double negations cancel each other out), arrive at the result in the second line of (14).

(14) It is not the case that Paul ate some of the eggs. $\chi_{\rightarrow}$ Paul ate all the eggs (Gazdar 1979, p. 56).

But clearly, this result is incorrect for (14) - the putative implicature contradicts the assertion. The root of the problem is that negation reverses scales (Horn 1972, p. 33; Atlas and Levinson 1981, p. 33). Replacing some with all, when it is not in the scope of negation, often yields a stronger proposition, and if that is the case, Gazdar's procedure yields the right result. But when some occurs in the scope of negation as in (14), replacing it with all yields a weaker claim. That is why Gazdar had to block his procedure from applying in this case.

Gazdar's solution to the negation problem - locking implicature computation from applying to any scalar term in the scope of a logical operator - is stipulative, and does not predict the implicature reversal actually observed (Atlas and Levinson 1981, p. 33 and others). The negation problem shows that it's not sufficient to replace a scalar term only with the next stronger item on its scale as Gazdar does, since this only leads to the right implicature if the scalar item is in an upward entailing context. In the scope of negation, however, we need to replace a scalar term with the next weaker

\footnotetext{
7 To my knowledge examples like (14) are the only reason Gazdar restricts his mechanism to occurrences of scalar terms occurring in the scope of no other logical operator.
} 
item on its scale to generate the right implicature, because this leads to a stronger assertion. This could be done by testing for each occurrence of a scalar item, whether it occurs in an upward or downward entailing environment. A more general solution, however, is to always consider both replacements, and compute independently which replacement results in a stronger claim. While this intuition seems to have been around since Horn (1972), I am not aware of any technical implementation of this idea. I propose the following terminology to capture the sentences derivable by replacements of scalar terms with terms from the same scale: ${ }^{8}$

(15) A sentence $\psi$ is a one-step scalar alternative of $\phi$ if the following two conditions hold:

a. $\phi \neq \psi$

b. there are scalar expressions $\alpha$ and $\alpha^{\prime}$ which both occur on the same scale $C$ such that $\psi$ is the result of replacing one occurrence of $\alpha$ in $\phi$ with $\alpha^{\prime}$.

(16) A sentence $\psi$ is a scalar alternative of $\phi$ if there is a sequence $\left(\phi_{0}, \ldots, \phi_{n}\right)$ with $n \geq 0$ and $\phi_{0}=\phi$ and $\phi_{n}=\psi$ such that, for all $i$ with $1 \leq i \leq n, \phi_{i}$ is a one-step scalar alternative of $\phi_{i-1}$.

In the following, I use the notation $\operatorname{ScalAlt}(\phi)$ for the set of all scalar alternatives of a sentence $\phi$.

I propose that a scalar alternative of an asserted sentence leads to an implicature only if the scalar alternative is logically stronger (in the sense of asymmetric entailment) than the assertion. This is given in (17).

(17) $\neg \psi^{\prime}$ is an scalar implicature of $\psi$ if the following three hold:

a. $\quad \psi^{\prime}$ is a scalar alternative of $\psi$

b. $\psi^{\prime}$ entails $\psi$

c. $\psi$ does not entail $\psi^{\prime}$

Proposal (17) solves the negation problem: While an implicature is blocked in Gazdar's example (14), there's an implicature in the reverse direction in (18). This implicature follows by replacing all with some. This leads to a logically stronger scalar alternative in the scope of negation.

(18) It's not the case that Paul ate all of the eggs.

$\sim$ Paul ate some of the eggs.

\footnotetext{
8 Note that from this point on quantitative scales themselves do not need to be represented as ordered lists anymore. It would be sufficient to represent them as plain sets. I shall stick to the tradition though.
} 


\subsection{Crossing Scales}

The proposal just developed makes a prediction for the implicatures of sentences that contain more than one scalar term. Abstractly, we can view a sentence with two occurrences of a scalar term as $\phi(X, Y)$, where $X$ is an element of the quantitative scale $Q_{X}$ and $Y$ an element of the quantitative scale $Q_{Y}$. The set of scalar alternatives of $\phi(X, Y)$ is then isomorphic to the cross product of the two scales $Q_{X}$ and $Q_{Y}$. This is apparent from the fact that (19) holds:

$$
\begin{aligned}
& \text { ScalAlt }(\phi(X, Y))=\left\{\phi\left(X^{\prime}, Y^{\prime}\right) \mid X^{\prime} \text { an element of } Q_{X}, Y^{\prime}\right. \text { an } \\
& \text { element of } \left.Q_{Y}\right\}
\end{aligned}
$$

The predicted implicatures arise from all those sentences $\phi\left(X^{\prime}, Y^{\prime}\right)$ that entail $\phi(X, Y)$. To a large extent this prediction is borne out, though as we shall see the recalcitrant (5) still remains a problem.

Consider first examples where neither of the two scalar expressions is in the scope of the other, nor in the scope of any other logical operator. For such cases, Gazdar's procedure actually makes the same prediction as the system developed above. It is not easy to come up with examples of this kind, but (20) and (21) can, I think, be argued to do so. The predicted implicatures are shown below these two examples. In each case, the third implicature is actually entailed by the first or the second one, hence I enclosed it in parentheses.

(20) Kai ate peas or broccoli on Monday or Tuesday. $\sim \neg$ (Kai ate peas and broccoli on Monday or Tuesday)

$\leadsto \neg$ (Kai ate peas or broccoli on Monday and Tuesday)

$(\sim \neg$ (Kai ate peas and broccoli on Monday and Tuesday),

(21) The fathers of some of the boys knew some of the answers.

$\sim \neg$ (the father of every boy knew some of the answers)

$\sim \neg$ (the father of some of the boys knew all of the answers)

( $\sim \neg$ (the father of all of the boys knew all of the answers))

Are these implicatures actually correct? My intuition about these examples is a little unclear. But if I consider them as answers to a relevant question, I think they are in accord with the prediction. ${ }^{9}$ For (20) such a context would

\footnotetext{
9 More specifically, my intuition for (21) is that the first two implicatures could be false, but only if there is a falsifying instance for the indefinite that does not overlap with the verifying instance for the corresponding indefinite in the asserted sentence. For example,
} 
be provided by the question Did Kai eat any green vegetables this week? for (20), and for (21) by Did the fathers know any of the answers? for (21).

A further argument that (20) indeed has the predicted implicatures is provided by the data in (22).

(22)a. The fathers of some of the boys knew some of the answers, and possibly even the fathers of all of the boys knew some of the answers.

b. The fathers of some of the boys knew some of the answers, and possibly the fathers of some of the boys even knew all of the answers.

As mentioned in Section 1.1 above, Horn (1972, p. 30) argues that suspender clauses (i.e., clauses that cancel an implicature) like those initiated by and possibly even are only acceptable if they suspend an actual implicature. Therefore, the acceptability of the data in (22) argues that (21) indeed has the two first implicatures given in (21).

Now consider sentences where a scalar term is in the scope of another operator. First look at scalar expressions in the scope of conjunction in the examples (23) and (24). Gazdar's mechanism does not predict scalar implicatures for these examples, since here both occurrences of scalar terms other than and are in the scope of and in both examples. The implicatures predicted by the proposal currently under investigation are shown below the assertion in (23) and (24).

(23) John read A or B and watched C or D.

$\sim \neg($ John read A and B and watched C or D)

$\leadsto \neg($ John read A or B and watched C and D)

$\leadsto \neg($ John read A and B and watched C and D)

(24) Kai ate some of the strawberries and Hannes ate some of the carrots.

$\leadsto \neg$ (Kai ate all of the strawberries and Hannes ate some of the carrots)

$\leadsto \neg$ (Kai ate some of the strawberries and Hannes ate all of the carrots)

$\leadsto \neg$ (Kai ate all of the strawberries and Hannes ate all of the carrots)

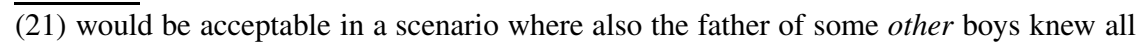
of the answers. At present, I have no account of this intuition, but I would like to come back to this issue in some future research. 
For both (23) and (24), it is difficult to judge whether the implicatures as stated above are correct since they are very complicated statements. The implicatures that seem salient with (23) and (24) seem to be actually those in (25) and (26) respectively. ${ }^{10}$

(25)a. John didn't read A and B.

b. John didn't watch C and D.

(26)a. Kai didn't eat all of the strawberries.

b. Hannes didn't eat all of the carrots.

However, I argue now that (25) and (26) actually arise from the implicatures noted in (23) and (24). The argument proceeds from the following assumption, which is as far as I know undisputed: For the felicitous assertion of an sentence, not only its implicatures must be true, but also the assertion itself. This is captured by Grice (1967) maxims of quality, specifically his supermaxim - 'Try to make your contribution one that is true'. Hence, any entailment drawn from the assertion and its implicatures will itself be necessarily true in any situation where a sentence can be felicitously asserted. It follows therefore that any such entailment except those entailed by the assertion alone has the same pragmatic status as an implicature of the sentence. Now observe that both sentences in (25) are actually entailed by the assertion and the implicatures noted in (23), while the assertion of (23) alone does not entail either one of the sentences in (25). Therefore, it follows that both (25a) and (25b) are predicted to be implicatures of (23), and in the same way both (26a) and (26b) are predicted as implicatures of (24). As this analysis generalizes to all examples with scalar terms in the scope of conjunction, my proposal accounts for the salient implicatures of such examples.

Further support for my proposal comes from examples with scalar expressions in the scope of negation and other downward entailing operators. In (18), I showed already that the proposal correctly accounts for the implicature reversal in the scope of negation. The same implicature reversal is observed in other downward entailing contexts: (27) illustrates an implicature from and to $o r$ in the restriction of a universal quantifier.

(27) Every boy who eats peas and broccoli will stay healthy. $\sim$ Not every boy who eats peas or broccoli will stay healthy.

\footnotetext{
10 The implicatures in (25) and (26) are exactly the implicatures that the first and the second conjunct of (24) have when they occur as single sentences, as pointed out by Chierchia (2002).
} 
Consider also an example with two scalar expressions in the scope of negation. I found examples of this type where one scalar expression is not also in the scope of another difficult to form a judgement on. Consider, though, (28) with two occurrences of every in the scope of negation, where one occurrence of every c-commands the other. The predicted implicatures, which are indicated in (28), are borne out.

(28) It's not the case that every child knows every adult.

$\sim$ Some child knows every adult.

$\sim$ Every child knows some adult.

$(\sim$ Some child knows some adult.)

Finally consider further examples where one scalar expression occurs in the scope of another. This class of examples will be most relevant for the remainder of this paper. Consider first the examples (29) and (30). Again I show the predicted implicatures below each of the examples.

(29) Winnie is allowed to smoke a cigarette or a cigarillo today.

$\sim$ Winnie isn't required to smoke a cigarette or a cigarillo today.

$\sim$ Winnie isn't allowed to smoke a cigarette and a cigarillo today.

$(\sim$ Winnie isn't required to smoke a cigarette and a cigarillo today.)

(30) Some of the children found some of their presents.

$\sim$ Not all of the children found some of their presents.

$\sim$ Some of the children didn't find all of their presents.

( $\sim \neg$ (All of the children found all of their presents))

Again, the predicted implicatures are intuitively correct in both (29) and (30).

\subsection{The Disjunction Problem Again}

The previous section showed that the account makes a number of correct predictions in cases where Gazdar's account is insufficient. However, the account still has at least one problem. Specifically, examples with a scalar expression in the scope of disjunction. In (31), example (5) is repeated with the two implicatures that were observed above. 
(31) Kai had the broccoli or some of the peas last night.

$\sim$ Kai didn't have the broccoli and some of the peas last night.

$\sim$ Kai didn't have all of the peas last night.

To see what the proposal under discussion predicts, observe the set of scalar alternatives of (31) in (32).

(32) $\operatorname{ScalAlt}(31)=\{a, b, c\}$

a. Kai had the broccoli or all of the peas last night.

b. Kai had the broccoli and some of the peas last night.

c. Kai had the broccoli and all of the peas last night.

Scalar implicatures arise from those scalar alternatives that asymmetrically entail (31). Since all three of (32a-c) entail (31) and not vice versa, three implicatures are predicted. While the predictions of $(32 b)$ and $(32 c)$ are harmless, (32a) predicts that (33) should be an implicature of (31).

(33) $\neg$ (Kai had all of the peas or the broccoli last night.)

This result, however, is wrong. (33) entails that Kai did not have the broccoli last night. But, clearly (31) does not implicate that Kai did not have the broccoli last night. Furthermore, simply blocking (33) as an implicature would not solve the problem since then the implicature that Kai did not have all of the peas last night would not follow anymore. ${ }^{11}$

As I mentioned above the problem occurs more generally with scalar expressions in the scope of disjunction. Consider Simons's (1995, p. 94) discussion of (34) (see also footnote 4).

(34) $\quad$ A or $(\mathrm{B}$ or $\mathrm{C})$
a. $\sim \operatorname{not}(\mathrm{A}$ and $\mathrm{B})$
b. $\sim \operatorname{not}(\mathrm{A}$ and $\mathrm{C})$
c. $\sim \operatorname{not}(\mathrm{B}$ and $\mathrm{C})$

Simons argues that (34) actually has the implicatures shown here. These are equivalent to the claim that only one out of $\mathrm{A}, \mathrm{B}$ and $\mathrm{C}$ is true. The current proposal however predicts the implicatures in (35).

(35)a. $\neg($ A and $(\mathrm{B}$ or $\mathrm{C}))$

b. $\neg(\mathrm{A}$ or $(\mathrm{B}$ and $\mathrm{C}))$

11 In Section 1.3, I pointed out that Hirschberg's (1985) proposal runs into exactly the problem observed in the text here. 
Of these, (35a) is correct as can be seen by considering that (35a) is equivalent to $\neg(A$ and B) and $\neg(A$ and $C)$, which is the conjunction of (34a) and (34b). (35b), however, entails $\neg A$ and therefore cannot be an implicature of (34) since (34) could not be felicitously asserted if $\neg \mathrm{A}$ holds. If, however, the implicature (35b) was blocked somehow the account does not generate the implicature (34c).

\section{DisJunCtion AND the Epistemic SteP}

\subsection{The Scale of Disjunction}

In this section, I consider the cases with a disjunction that has a scalar term in its scope. We saw above that the proposal developed in Section 2.1 did not predict the second implicature in example (36) (repeated from (5)).

(36) Kai had the broccoli or some of the peas last night.

$\sim$ Kai didn't have the broccoli and some of the peas last night.

$\sim$ Kai didn't have all of the peas last night.

Which of the assumptions going into the proposal in Section 2.1 could be changed to predict this implicature? A straightforward way of adding the implicature to the set of implicatures predicted by the proposal is to assume the more elaborate scale for disjunction in (37).

The Scale of Disjunction

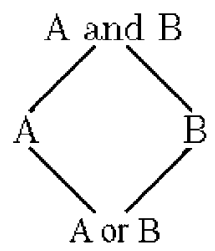

The diamond shape is used because, in contrast to other cases of quantitative scales, the proposed scale of disjunction is a set that is only partially ordered by entailment.

If the scale of a disjunction is indeed the one shown in (37), the set of scalar alternatives of (36) includes the sentence (38). Namely, (38) can be generated by first replacing the disjunctive statement with just the second disjunct and also replacing the scalar item some with all.

(38) Kai had all the peas last night. 
From (38), it immediately follows that the second implicature in (36) is predicted to be an implicature of (36).

The assumption that (37) is the scale of disjunction raises at least two problems. The first problem is related to the fact that unlike the familiar examples of quantitative scales Horn (1972) introduced, (37) does not have single lexical items, but entire sentences on it. (37) therefore really is not a single scale, but a scale schema which has an instantiation for any two sentences $\mathrm{A}$ and $\mathrm{B}$. This predicts, however, that any sentence A is a scalar item since it is on infinitely many scales that instantiate the schema (37). It follows that assertion of A is predicted to implicate $\neg$ (A and B) for any B such that $A$ does not entail the scalar alternative $A$ and $B$. Now, take into account that A does not entail A and B if and only if B is not entailed by A. Also note that the assertion A and the predicted implicature $\neg$ (A and B) entail $\neg B$. Therefore, it follows from the account that for any B that is not entailed by A, assertion of A should implicate $\neg$ B.

This prediction is clearly generating too many implicatures: Asserting 'It's raining' in most discourses does not implicate 'John sneezed'. ${ }^{12}$ One possible attempt to rule out this prediction would start from the following observation: Asserting A is predicted to not just entail $\mathrm{B}$, but also $\neg \mathrm{B}$ for any B that neither entails A nor is entailed by A. Hence it seems plausible that, because these two implicatures contradict each other, they cancel each other out. However, this account relies on first computing for any B also the implicature $\neg \mathrm{B}$ that contradicts it, which looks like an implausibly inefficient model for a cognitive mechanism. Therefore, I would like to introduce a shortcut into the system that blocks such implicatures in a more direct manner. Namely, I propose that there are two binary operators defined as in (39), which do not correspond to any pronounceable words of any language as far as I know, ${ }^{13}$ but occur on the scale of disjunction. The scale of disjunction is then (40), rather than the scale schema in (37). ${ }^{14}$

\footnotetext{
12 This implicature is observed in very special discourses. For example, in answer to the question 'Can you tell me whether it is raining and whether John sneezed?', the implicature does seem to be present. But here it seems likely that the context explicitly sets up the scale of 〈'It's raining and John sneezed', 'John sneezed'〉.

13 It would follow from the Gricean maxim of brevity that $\mathrm{L}$ and $\mathrm{R}$ could never be used in an assertion if they were pronounceable, hence, it is not surprising that they would be unpronounceable.

14 Possibly these operators are useful for focus semantics as well. For example, it seems in (i), with focus on $o r$, that the operator $\mathrm{L}$ is an alternative to or for focus semantics as well.
}

(i) I only claimed that A or B is true, not that A is true. 
(40)<smiles>C1[14CH]C[GeH2]1</smiles>

Because the scalar items $\mathrm{A} R \mathrm{~B}$ and $\mathrm{A} \mathrm{L}$ B are formally distinct from the sentence $\mathrm{B}$, though the two are equivalent, this proposal does not have the problem that came up in (37). Evidently the adoption of (40) is more of a technical trick, than a real solution for the problem just discussed. However, the intuition underlying it, that the use of the word or drives the computation of scalar implicatures, also underlies Horn's quantitative scales and seems sound. Therefore, I hope future research will show that the apparent clumsiness here is due to my technical execution, not the idea. For the discussion below, the difference between (37) and (40) is actually irrelevant, hence I will talk as if (37) is the scale of disjunction since the scalar alternatives it leads to are easier to parse.

The second problem with (37) is more severe but I believe also has a more fruitful effect. The problem is that, for a statement of the form A or $\mathrm{B}$, the scale in (37) predicts the implicatures $\neg \mathrm{A}$ and $\neg \mathrm{B}$ since both A and $\mathrm{B}$ are scalar alternatives of A or B. But, these two predicted implicatures do not actually seem to be observed. For example, it is odd to cancel one of these putative implicatures as (41) shows.

(41) \#It's raining or John sneezed and possibly it's even raining.

Moreover, the two putative implicatures $\neg \mathrm{A}$ and $\neg \mathrm{B}$ together contradict the assertion A or B.

In the following section, I argue that this problem should lead us to adopt a further revision of Gazdar (1979) analysis of implicatures, while maintaining (40) as the scale of disjunction.

\subsection{The Epistemic Status of Implicatures}

In this section, I argue that the second problem discussed in the previous section is resolved by considering the epistemic status of implicatures. My starting point in this investigation has been the mechanism Gazdar (1979) proposes to predict the implicatures of a sentence $\phi$. Soames (1982, p. 521) and Horn (1989, p. 432, n. 5) criticize one aspect of Gazdar's mechanism: namely, the epistemic commitment assigned to the implicatures by 
Gazdar's proposal. While both Soames and Horn agree that implicatures of $\phi$ arise from certain stronger statements $\psi$, they argue that it only follows from Gricean maxims of conversation that $\psi$ is uncertain, rather than that $\psi$ is certainly false as Gazdar claims. ${ }^{15}$ Following Gazdar, I'll employ the $\mathrm{K}$-operator to express epistemic certainty, and the P-operator for epistemic possibility (Hintikka 1962). Using this terminology, Soames and Horn's claim is that what is implicated is $\neg \mathrm{K} \psi$ rather than $\mathrm{K} \neg \psi$. Soames and Horn point out that Gazdar's $\mathrm{K} \neg \psi$ would follow from their $\neg \mathrm{K} \psi$ only if some additional knowledge is assumed, for example the knowledge that $\mathrm{K} \psi \vee \mathrm{K} \neg \psi$ holds. They suggest that people may often make some such additional assumption in conversation which then explains the fact that Gazdar's proposal seems to make the right empirical prediction in many cases.

The proposal in Section 2.1 adopted the assumption from Gazdar that the procedure directly arrives at a set of epistemically certain implicatures of the form $\mathrm{K} \neg \psi$. Therefore, the criticism mentioned applies to this proposal in the same way. In the analysis I develop for the disjunction problem in the following, the point Soames and Horn raise is an important part of the solution. I claim that the distinction between the "uncertain $\psi$ " implicatures that follow from the Gricean maxims of conversation and the "certain not $\psi$ " implicatures Gazdar predicts is important for the explanation of the implicatures of disjunction. Therefore, I introduce a terminological distinction between these two types of implicatures: I will call the Soames/Horn are type implicatures primary implicatures, and the Gazdar-type implicatures secondary implicatures. The set of all implicatures predicted by this analysis is then the union of the sets of primary and secondary implicatures.

(42) If $\psi \in \operatorname{ScalAlt}(\phi)$ and $\psi \Rightarrow \phi$ and not $\phi \Rightarrow \psi$, then $\neg \mathrm{K} \psi$ is a primary implicature of $\phi$.

(43) If $\neg \mathrm{K} \psi$ is a primary implicature of $\phi$ and $\mathrm{K} \neg \psi$ is consistent with the conjunction of $\phi$ and all primary implicatures of $\phi$, then $\mathrm{K} \neg \psi$ is a secondary implicature of $\phi$.

The condition in (43) rules out the case in which a secondary implicature contradicts the conjunction of the primary implicatures and the assertion. This assumption introduces a hierarchy amongst the implicatures, and

\footnotetext{
15 The following discussion is framed in terms of impersonal certainty of a specific proposition, rather than whether the speaker is certain or not of some proposition as assumed e.g., by Gamut (1991). The difference, however, is only in the notation - I want to stick with the impersonal epistemic K-operator that Gazdar (1979) uses.
} 
one must ask why it is not possible to cancel the primary implicature or the assertion, rather than the secondary implicature if there is a conflict between the two. However, this hierarchy follows if we consider the sets of assumptions that go into the reasoning that one of these is true. To reason that the assertion is true, one only needs to appeal to the assumption that the speaker making an assertion is obeying one of Grice's quality maxims. To reason that the primary implicatures arise, one needs the assumption that the speaker making an assertion is obeying all of Grice's maxims. ${ }^{16}$ Finally, to reason for a secondary implicature $\mathrm{K} \neg \psi$ one has to assume that the speaker obeys all the Gricean maxims to derive $\neg \mathrm{K} \psi$ and furthermore that $\mathrm{K} \psi \vee \mathrm{K} \neg \psi$ or some stronger assumption is justified.

The distinction between primary and secondary implicatures now leads to a new prediction when combined with the scale for disjunction in (37). Consider a statement of the form A or B. From the scalar alternatives in (37), the primary implicatures in (44) follow straightforwardly.

$$
\begin{aligned}
\text { (44)a. } & \sim \neg \mathrm{K} \mathrm{A} \\
\text { b. } & \sim \neg \mathrm{K} \mathrm{B} \\
\text { c. } & \sim \neg \mathrm{K}(\mathrm{A} \text { and } \mathrm{B})
\end{aligned}
$$

To understand what the primary implicatures in (44) mean intuitively, first note that $(44 c)$ is entailed by $(44 a, b)$ and therefore not informative. Furthermore, observe that from (44b) together with the assertion that A or B is true, it follows that A must be possible. Similarly it follows from (44a) the assertion that $\mathrm{B}$ must also be possible. Using $\mathrm{P}$ to express epistemic possibility, this leads to the two implicatures in (45).

$$
\begin{array}{rr}
\text { (45)a. } & \text { P A } \\
\text { b. } & \text { P B }
\end{array}
$$

The implicatures $(45 \mathrm{a}, \mathrm{b})$ are already observed by Gazdar (1979, p. 50, (41)). Therefore, that we predict these implicatures is empirically correct. Gazdar accounts for the implicatures $(45 \mathrm{a}, \mathrm{b})$ as clausal quantity implicatures. It does, however, seem desirable to eliminate this concept which Gazdar only makes use of to account for the possibility of implicatures of disjunction discussed here and for an implicature in conditionals. Here,

\footnotetext{
16 I have not investigated how cases where a proper subset of all maxims gives rise to a primary implicature are to be treated. Maybe this can force the cancellation of primary implicatures that are drawn from all the maxims. Or, maybe the hearer really makes just one assumption about the speaker, namely, that he is cooperative, which is equivalent to the conjunction of all of Grice's maxims.
} 
I have shown that clausal quantity implicatures are not necessary for the account of disjunction. It seems possible to me to also account for conditionals without clausal quantity implicatures (cf. von fintel 2000). ${ }^{17}$

Which of the primary implicatures in (44) give rise to secondary implicatures? To answer this question, we need to decide which of the potential secondary implicatures are consistent with the conjunction of all primary implicatures and the assertion. Consider first the secondary implicature arising from (45a), namely $\mathrm{K} \neg \mathrm{A}$. This secondary implicature is blocked because it follows from the assertion $\mathrm{K}(\mathrm{A}$ or $\mathrm{B})$ and the primary implicature (45b), that A must possibly be true. The secondary implicature $\mathrm{K} \neg \mathrm{B}$, which could arise from (45b), is blocked in a similar way. Finally, consider the secondary implicature $\mathrm{K} \neg(\mathrm{A}$ and $\mathrm{B})$. This implicature is consistent with the assertion and the primary implicatures, and therefore predicted to actually arise. This prediction is borne out: This implicature is in fact the exclusiveness implicature of disjunction illustrated by (1) at the beginning. This result is summarized in (46):

(46) Secondary implicatures of A or B:
a. $\not \Varangle \mathrm{K} \neg \mathrm{A}$ (blocked)
b. $\not \Varangle \mathrm{K} \neg \mathrm{B}$ (blocked)
c. $\sim \mathrm{K} \neg(\mathrm{A}$ and $\mathrm{B})$ (Exclusiveness)

\subsection{Scalar Terms in the Scope of Disjunction}

Now, we are ready to address example (5) and the general class of problematic examples it exhibits: examples with a scalar term in the scope of disjunction. I repeat example (5) in (47).

(47) Kai had the broccoli or some of the peas last night.

Consider first the list of primary implicatures predicted by the approach of the previous section.

(48)a. $\quad \neg \mathrm{K}(\mathrm{Kai}$ had some of the peas last night)

b. $\neg \mathrm{K}(\mathrm{Kai}$ had the broccoli last night)

c. $\neg \mathrm{K}$ (Kai had the broccoli and some of the peas last night)

d. $\neg \mathrm{K}(\mathrm{Kai}$ had all of the peas last night)

\footnotetext{
17 Gazdar (1979, p. 136) argues that if a clausal implicature conflicts with a scalar implicature the latter is cancelled. This is reminiscent of the hierarchy between primary and secondary implicatures I proposed. A difference might be, though, that the hierarchy I assumed can be derived in the way shown above.
} 
e. $\neg \mathrm{K}$ (Kai had the broccoli or all of the peas last night)

f. $\neg \mathrm{K}$ (Kai had the broccoli and all of the peas last night)

Again, all of these primary implicatures seem unproblematic.

Consider now the secondary implicatures that potentially arise from (48). As we have already seen in the consideration of A or B in (44) above, the secondary implicatures from $(48 \mathrm{a}, \mathrm{b})$ are blocked, while (48c) gives rise to exclusivity as a secondary implicature.

Now consider the secondary implicature that arises from (48d), that it's certain that Kai did not have all the peas last night. This implicature is consistent with the assertion (47) and the primary implicatures in (48), and therefore predicted to be available. As we saw in Sections 1.2 and 1.3 above, this particular implicature was not predicted by previous accounts.

Next consider the secondary implicature that would arise from (48e). It would say that it's certain that Kai did not have the broccoli and that he did not have all of the peas last night. This secondary implicature is also blocked because it is not consistent with the primary implicatures together with the assertion. Specifically, it contradicts the possibility implicature that Kai possibly had the broccoli last night, which is entailed by the assertion and the primary implicatures as I showed in the previous section.

Finally, the secondary implicature arising from (48f) is that certainly Kai did not have the broccoli and all of the peas last night. This implicature is not blocked, but, since it is entailed by the secondary implicature that Kai certainly did not have all of the peas, it also does not yield any new information.

In sum, we have therefore shown that the two secondary implicatures in (49) are predicted by the approach developed in the previous section.

$$
\begin{aligned}
& \sim \mathrm{K} \neg(\text { Kai had some of the peas and the broccoli last night }) \\
& \sim \mathrm{K} \neg(\text { Kai had all of the peas last night })
\end{aligned}
$$

These are the two implicatures that the example (5) was argued to have. This concludes my account for example (5).

To see that the solution generalizes to other cases of a scalar term in the scope of disjunction, consider now an example with multiple disjunction. In (50), example (34) is repeated from above. Recall that Simons (1998) observes the three implicatures in $(50 \mathrm{a}-\mathrm{c})$.

$$
\text { (50) } \begin{aligned}
& \text { A or }(\mathrm{B} \text { or } \mathrm{C}) \\
\text { a. } & \sim \operatorname{not}(\mathrm{A} \text { and } \mathrm{B}) \\
\text { b. } & \sim \operatorname{not}(\mathrm{A} \text { and } \mathrm{C}) \\
\text { c. } & \sim \operatorname{not}(\mathrm{B} \text { and } \mathrm{C})
\end{aligned}
$$


The discussion of (34) above showed that the proposal under discussion there did not predict implicature (50c). Consider now the nine primary implicatures generated by the present proposal in (51).

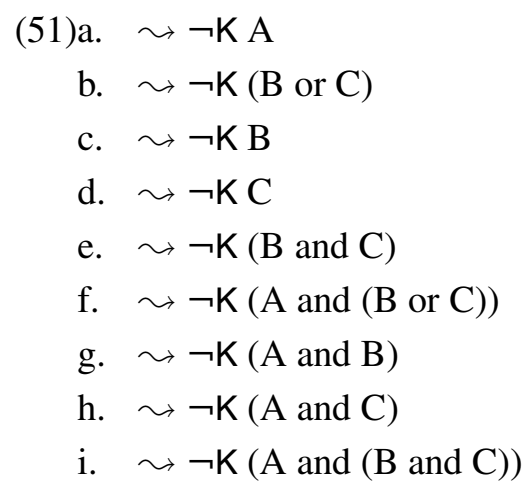

As in the case of a single disjunction in (44), the primary implicatures entail that each of A, B, and C must be possible: PA follows from (51b) together with the assertion, and, considering (51f) entails both $\neg \mathrm{K}$ (A or C) and $\neg \mathrm{K}$ (A or B), P B and P C as well follow (51f) together with the assertion.

Now consider the secondary implicatures derivable from the primary ones in (51). The potential secondary implicatures derivable from (51ad) are inconsistent with the possibility implicatures just noted. The same holds for the potential secondary implicature from $(51 \mathrm{~b})$, which is equivalent to $\mathrm{K}(\neg \mathrm{B}$ and $\neg \mathrm{C})$.

Hence only the secondary implicatures derived from (51e-i) are consistent with the conjunction of the assertion and the primary implicatures which are shown in (52).

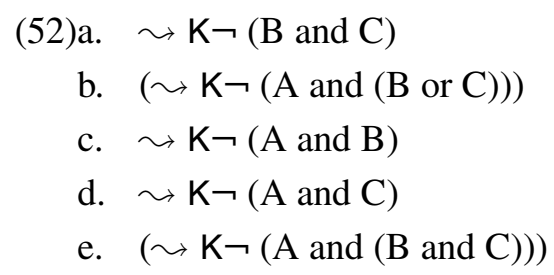

The secondary implicatures (52a), (52c), and (52d) are exactly the three exclusivity implicatures Simons (1998) observed. Since (52b) and (52e) are entailed by the three exclusivity implicatures, my proposal predicts exactly the correct secondary implicatures. 


\section{SUMmARY AND OUTLOOK}

In this paper, I argued that Gazdar's (1979) claim that scalar terms in the scope of a logical operator do not give rise to scalar implicatures is incorrect. I propose a system for the computation of scalar implicatures without such a restriction in Section 2.1 and then show in Section 2.2 that this system has better empirical coverage that Gazdar's. The remaining problems, which I then address in Section 3, are examples with a scalar term in the scope of disjunction like (53) and (54).

(53) Kai had some of the peas or the broccoli last night.

$\sim$ Kai didn't have some of the peas and the broccoli last night.

$\sim$ Kai didn't have all of the peas last night.

$$
\begin{aligned}
& \text { A or }(\mathrm{B} \text { or } \mathrm{C}) \\
& \sim \neg(\mathrm{A} \text { and } \mathrm{B}) \\
& \sim \neg(\mathrm{A} \text { and } \mathrm{C}) \\
& \sim \neg(\mathrm{B} \text { and } \mathrm{C})
\end{aligned}
$$

My solution has two parts to it: Part one is the assumption that the scale of disjunction is not $\langle$ or, and $\rangle$, but such that individual disjuncts $\mathrm{A}$ and $\mathrm{B}$ are also scalar alternatives of a disjunction A or B as shown in (37). Part two is the assumption that the computation of scalar implicatures proceeds in two steps: First, primary implicatures of the form "The speaker is not certain whether $\psi$ holds" are computed for certain $\psi$. In the second step, primary implicatures are strengthened to implicatures of the form "The speaker is certain that $\psi$ doesn't hold," which I have called secondary implicatures.

It is important to note that these two assumptions not only serve to provide an account for examples like (53) and (54), but that each of them also is independently supported: The assumption that there is an epistemic step from primary to secondary implicatures is required to account for a discrepancy between the Gricean justification for implicatures and the empirical facts. Namely, Gricean reasoning only yields primary implicatures (Horn 1989; Harnish 1976), and some additional assumption that people make in discourse is needed to account for the fact that actually secondary implicatures correspond to our intuitions. My contribution here has been to show one case in which the step from primary to secondary implicatures is blocked because the additional assumption normally made to justify this step contradicts the assertion and its primary implicatures.

The other assumption used in the account of (53) and (54) has been that the scalar alternatives of a disjunction "A or B" include the individual disjuncts "A" and "B". This assumption is independently supported because it 
yields a straightforward account of Gazdar's clausal quantity implicatures that disjunctions give rise to. Specifically, these are for an assertion "A or B" the implicatures that the speaker believes that A might be true and also that B might be true. As I argue in Section 3.2, Gazdar's account of these two implicatures is less satisfying than mine because mine requires no additional assumptions.

\subsection{Outlook}

The main point of this paper is that an account of the implicatures of examples like (53) and (54) in the Gricean framework is possible. The account I developed requires some modifications compared to previous linguistic implementations of Gricean intuitions, but is I believe nevertheless consonant with the general picture Grice has advocated. In particular, my account still derives implicatures from general assumptions about the use of sentences in discourse.

As I mentioned above, Chierchia (2002) uses examples like (53) and (54) to motivate a departure from the Gricean picture. As I have shown that a Gricean account of these is possible, this particular claim of Chierchia's is not valid any longer. Chierchia, however, adduces further interesting evidence that he claims argue against the Gricean picture. While I cannot conclusively discuss all the issues Chierchia raises, I want to show in the following that the issues he raises are complicated, especially since the empirical facts are less than clear.

One issue is the implicatures of bare cardinals like three. Horn (1972) proposes that a cardinal $n$ in many cases has the meaning of at least $n$, but via a scalar implicature acquires an interpretation paraphrasable as exactly $n$ in most contexts. As however Horn (1972) already discusses, this analysis cannot account for all uses of numeral expressions, for example intonational factors affect the analysis (see for example Landman 1998, 2000; Kadmon 2001 for more discussion). In this paper, I leave it open whether the exactly-interpretation of bare cardinals really arises as a scalar implicature.

One other relevant class of data Chierchia discusses involves scalar terms in the scope of conjunction. However, I already show in the discussion of (23) and (24) that my proposal accounts for such examples correctly.

A more difficult issue Chierchia raises are scalar terms in the scope of a universal. In particular, Chierchia discusses an example similar to (55).

(55) Every student wrote a paper or made a classroom presentation (Chierchia 2002 (35c)). 
My account predicts for (55) the secondary implicature in (56), which arises from the replacement of $o r$ with and.

(56) $\quad \mathrm{K}$ (Not every student wrote a paper and made a classroom presentation)

Chierchia claims though that (56) is too weak, and really (56) has the implicature in (57):

K(No student wrote a paper and made a classroom presentation)

At present, I hesitate to pronounce one of two predictions correct. It seems that Chierchia's (57) has some justification, but it is also natural for this example to assume that it's part of our background knowledge that no student would do more than is required of him. Then, if one of writing a paper and doing a presentation is sufficient, it would follow that no student did both. In example (58), this factor is ruled out because here a plausible background assumption is that MIT students study Chomsky's work very seriously.

(58) Every student at MIT has read LGB or Syntactic Structures.

In fact, Chierchia's strong implicature that no MIT student has read both $L G B$ and Syntactic Structures seems far less plausible for example (58). However, it remains to be seen whether examples like (55) or (58) generalize.

A third class of data that Chierchia discusses are scalar terms embedded under verbs of speaking and propositional attitude verbs. These data are very complicated to evaluate since often such verbs indicate that another speech act has taken place earlier in the context, and it is difficult to tell apart what are implicatures of this earlier speech act, and what are implicatures of the current speech act that contains these verbs. An exhaustive empirical investigation of this issue is therefore beyond the scope of my present paper.

A full-fledged comparison of the Gricean account with Chierchia's proposal therefore will have to wait for some future occasion. In addition to the data mentioned here, other data will probably be relevant. For example, for the computation of implicated presuppositions in Sauerland (2002), I crucially rely on the Gricean account. What I believe to have shown in this paper is that the Gricean account, when spelled out in a suitable manner, can deal with a number of examples that at first seem difficult to account for. 


\section{REFERENCES}

Atlas, J. D. and S. C. Levinson: 1981, 'It-Clefts, Informativeness, and Logical Form: Radical Pragmatics (Revised Standard Version)', in P. Cole (ed.), Radical Pragmatics, Academic Press, NY, pp. 1-61.

Chierchia, G.: 2002, 'Scalar Implicatures, Polarity Phenomena, and the Syntax/Pragmatics Interface', unpublished manuscript, University of Milan Bicocca (to appear in A. Belletti (ed.), Structures and Beyond, Oxford University Press, Oxford.).

Gamut, L.: 1991, Logic, Language, and Meaning, Volume 1, University of Chicago Press, Chicago, IL.

Gazdar, G.: 1979, Pragmatics: Implicature, Presupposition, and Logical Form, Academic Press, NY.

Grice, P.: 1975 [1967], 'Logic and Conversation', in P. Cole and J. L. Morgan (eds.), Speech Acts, Academic Press, NY, pp. 41-58.

Harnish, R.: 1976, 'Logical Form and Implicature', in T. Bever et al. (eds.), An Integrated Theory of Linguistic Ability, Crowell, New York, pp. 313-391.

Hintikka, J.: 1962, Knowledge and Belief, Cornell University Press, Ithaca, NY.

Hirschberg, J.: 1991 [1985], A Theory of Scalar Implicature, Garland, NY (PhD thesis, University of Pennsylvania, PA).

Horn, L. R.: 1972, 'On the Semantic Properties of Logical Operators in English', PhD thesis, University of California, LA.

Horn, L. R.: 1989, A Natural History of Negation, University of Chicago Press, Chicago, IL.

Kadmon, N.: 2001, Formal Pragmatics: Semantics, Pragmatics, Presuppositions, and Focus, Blackwell Publishers, Malden, MA, and Oxford, UK.

Landman, F.: 1998, 'Plurals and Maximalization', in S. Rothstein (ed.), Events and Grammar, Kluwer, pp. 237-271.

Landman, F.: 2000, Events and Plurality, Kluwer, Dordrecht.

Levinson, S. C.: 1983, Pragmatics, Cambridge University Press, Cambridge, UK.

Levinson, S. C.: 2000, Presumptive Meanings, MIT Press, Cambridge, MA.

Matsumoto, Y.: 1995, 'The Conversational Condition on Horn Scales', Linguistics and Philosophy 18, 21-60.

McCawley, J. D.: 1993, Everything that Linguists have Always Wanted to Know about Logic, 2nd edn, University of Chicago Press, Chicago, IL.

Sauerland, U.: 2002, 'The Present Tense is Vacuous', Snippets 6.

Schwarz, B.: 2000, 'On Long Coordinations', Talk at Tübingen University.

Simons, M.: 2000 [1998], Issues in the Semantics and Pragmatics of Disjunction, Garland, NY. (PhD thesis, Cornell University, Ithaca, NY.).

Soames, S.: 1982, 'How Presuppositions are Inherited: A Solution to the Projection Problem', Linguistic Inquiry 13, 483-545.

von Fintel, K.: 2000, 'Conditional Strengthening: A Case Study in Implicature', unpublished manuscript, MIT.

Department of Linguistics, $U-1145$

University of Conneticut

337 Mansfield Road

CT 06269-1145 Storrs

USA

uli@alum.mit.edu 
